Arq. Bras. Med. Vet. Zootec., v.69, n.2, p.437-444, 2017

\title{
Avaliação nutricional e energética da soja integral tostada para frangos de corte
}

\author{
[Nutritional and energetic evaluation of toasted full-fat soybean for broilers] \\ F.S. Dalólio, L.F.T. Albino, H.S. Rostagno, D.L. da Silva, M.L. Xavier Júnior, V.D. Oliveira \\ Universidade Federal de Viçosa - Viçosa, MG
}

\begin{abstract}
RESUMO
Objetivou-se determinar a composição química, os valores energéticos e os coeficientes de digestibilidade ileal verdadeira de aminoácidos de sojas integrais tostadas de cinco regiões. No primeiro experimento, foram utilizados 288 pintos de corte machos da linhagem Cobb 500, com 13 dias de idade e peso médio de $420,0 \pm 5,0 \mathrm{~g}$. O delineamento experimental utilizado foi inteiramente ao acaso, com seis tratamentos (cinco sojas integrais e uma ração referência) e oito repetições de seis aves. No segundo experimento, foram utilizados 288 frangos de corte machos da linhagem Cobb 500, com 24 dias de idade e peso médio de $865,0 \pm 20,0 \mathrm{~g}$. O delineamento experimental utilizado foi inteiramente ao acaso, com seis tratamentos (cinco sojas integrais e uma ração isenta de proteína à base de amido) e oito repetições de seis aves. Não houve diferença em relação aos teores de $\mathrm{EMA}_{n}$ e de $\mathrm{CEMA}_{\mathrm{n}}(\mathrm{P}>0,05)$ entre as sojas integrais. Os valores médios de $\mathrm{EMA}_{\mathrm{n}}, \mathrm{CEMA}_{\mathrm{n}}$ situaram-se entre 3152 e $3399 \mathrm{kcal} / \mathrm{kg}$ e 61,15 e $65,08 \%$, respectivamente. No entanto, houve diferença $(\mathrm{P}<0,05)$ entre os CAE, CANE e CPB das sojas integrais, e a amostra cinco obteve os menores valores. Os valores médios para os CAE e CANE da soja integral são de $88,96 \%$ e $87,53 \%$, respectivamente.
\end{abstract}

Palavras-chave: aminoácidos digestíveis, coeficientes, digestibilidade, energia, metabolizabilidade

\begin{abstract}
The goal of this paper was to determine the chemical composition, the energy values and the amino acid true ileal digestibility coefficients of toasted full-fat soybeans from 5 regions. In the first experiment, 288 chicken broilers from Cobb 500 lineage with 13 days old and average weight of $420.0 \pm 5.0 \mathrm{~g}$ were used. The experimental design was completely randomized with 6 treatments (5 full-fat soybean diets and 1 basal diet) and 8 replicates of 6 birds. In the second experiment, 288 chicken broilers from Cobb 500 lineage with 24 days old and average weight of $865.0 \pm 20.0 \mathrm{~g}$ were used. The experimental design was completely randomized with 6 treatments (5 full-fat soybean diets and 1 protein-free diet based on starch) and 8 replicates of 6 birds. There was no difference regarding the $A M E_{n}$ and $A M E C_{n}$ contents $(P>0.05)$ among the full-fat soybeans. The average values of $A M E_{n}, A M E C_{n}$ were between $3152-3399 \mathrm{kcal} / \mathrm{kg}$ and 61.15 to $65.08 \%$, respectively. However, there were differences $(P<0.05)$ between CEA, CENA and CPC of full-fat soybeans, and sample 5 obtained the lowest values. The average values for CEA and CENA of the full-fat soybean are $88.96 \%$ and $87.53 \%$, respectively.
\end{abstract}

Keywords: digestible amino acids, coefficients, digestibility, energy, metabolisability

\section{INTRODUÇÃO}

A soja integral, devido aos seus elevados teores de proteína e energia, apresenta-se como ótima alternativa ao farelo de soja e à inclusão de óleo vegetal nas rações de frangos de corte, sem prejuízo no desempenho produtivo (Costa et al.,

Recebido em 29 de setembro de 2016

Aceito em 4 de outubro de 2016

E-mail: felipesantos181@hotmail.com
2015). Além disso, diminui a dependência do setor avícola em relação ao farelo de soja, que é o principal ingrediente proteico de origem vegetal adicionado às rações. Apesar disso, tem sido reportado que o fornecimento exclusivo da soja integral em rações para frangos, mesmo após os processos térmicos, pode provocar efeitos indesejáveis devido à presença de fatores 
antinutricionais. Dentre estes, pode-se destacar os inibidores de protease, a presença de lecitinas, proteínas alergênicas, saponinas e demais alterações que podem ocorrer no momento do processamento dos grãos in natura (Valencia et al., 2009; Ravindran et al., 2014a).

A composição química dos alimentos, utilizados na confecção de rações, é um dos fatores que determinam o seu valor nutricional e a disponibilidade dos nutrientes para as aves (Vieira et al., 2014). Assim, o conhecimento dos teores de energia e de aminoácidos digestíveis dos alimentos adicionados às rações deve ser elucidado para a formulação de rações de maneira otimizada. Afinal, ambos atuam como limitantes do consumo, da excreção e do balanço de nitrogênio e no aproveitamento dos aminoácidos para a deposição proteica (Albino et al., 1992; Calderano et al., 2010).

No tocante à disponibilização de nutrientes para o metabolismo animal e às variações na composição química dos alimentos de origem vegetal, os fatores que mais provocam alteração são as variações inerentes ao clima, solo, cultivar de plantio e, também, ao tipo de processamento empregado. A tostagem do grão de soja integral é um mecanismo térmico com o objetivo de destruir os fatores indesejáveis com sucesso (Carvalho et al., 2008). No entanto, existem resultados conflitantes em relação ao processamento térmico e aos teores de energia e de aminoácidos digestíveis de um mesmo alimento oriundo de regiões e cultivares diferentes (Rodrigues et al., 2003; Ravindran et al., 2014b; Augustini et al., 2015; Heger et al., 2016). Com isso, torna-se pertinente a realização de análises constantes da composição química, bem como do aproveitamento energético e dos teores de aminoácidos digestíveis de alimentos de origem vegetal utilizados na formulação de rações para frangos de corte.

Diante do exposto, objetivou-se avaliar a composição química, os valores de energia metabolizável aparente, de energia metabolizável aparente corrigida para balanço de nitrogênio, de aminoácidos digestíveis e de seus respectivos coeficientes de digestibilidade de amostras de soja integral tostada, provenientes de cinco regiões do Brasil, em rações para frangos de corte.

\section{MATERIAL E MÉTODOS}

Todos os procedimentos deste estudo foram aprovados pelo Comitê de Ética no Uso de Animais de Produção (Ceuap) da Universidade Federal de Viçosa (UFV), sob o protocolo $\mathrm{n}^{\circ}$ $043 / 2015$.

Foram realizados dois experimentos nas instalações do setor de Avicultura da UFV. No primeiro experimento, foram utilizados 288 pintos de corte machos da linhagem Cobb 500, com 13 dias de idade e peso médio de $420,0 \pm 5,0 \mathrm{~g}$. Do primeiro ao $12^{\circ}$ dia de idade, os animais foram criados em piso com cobertura de maravalha, em um galpão de alvenaria, onde receberam ração adequada para o período inicial, segundo as recomendações de Rostagno et al. (2011).

Aos 13 dias de idade, as aves foram transferidas para gaiolas metálicas providas de comedouro tipo calha, bebedouro tipo nipple e uma bandeja coletora plastificada para a realização da coleta total de excretas para se determinarem os valores de energia metabolizável. O delineamento experimental utilizado foi inteiramente ao acaso, com seis tratamentos (cinco amostras de soja integral tostada de diferentes regiões e uma ração referência) e oito repetições com seis aves por unidade experimental. A ração basal, utilizada como referência, foi formulada à base de milho e de farelo de soja, segundo as recomendações de Rostagno et al. (2011) (Tab. 1). As dietas experimentais foram constituídas de $70 \%$ da dieta basal referência e $30 \%$ de inclusão de cada amostra de soja integral.

O período experimental foi de 10 dias, sendo cinco de adaptação e cinco de coleta de excreta total. As excretas coletadas foram colocadas em sacos plásticos, devidamente identificados, pesados e armazenados em freezer. Ao final do período de coleta, as excretas foram homogeneizadas e delas retiradas alíquotas, que foram colocadas em estufa de circulação forçada a $55^{\circ} \mathrm{C}$ para pré-secagem. Posteriormente, foram realizadas as análises laboratoriais, conforme metodologia proposta por Silva e Queiroz (2002). Com base nos resultados de nitrogênio e de energia bruta das rações e das excretas, foram calculados os valores de energia metabolizável aparente (EMA) e de energia metabolizável aparente corrigida para balanço de nitrogênio 
$\left(\mathrm{EMA}_{\mathrm{n}}\right)$, utilizando-se as equações propostas por Matterson et al. (1965). Posteriormente foram determinados os coeficientes de metabolizabilidade da energia aparente corrigida para balanço de nitrogênio $\left(\mathrm{CEMA}_{n}\right)$.

No segundo experimento, foram utilizados 288 frangos de corte com 24 dias de idade, da linhagem Cobb 500, com peso médio de $865,0 \pm 20,0 \mathrm{~g}$, para se determinarem os coeficientes de digestibilidade ileal verdadeira dos aminoácidos das amostras de soja integral. Os frangos foram distribuídos em delineamento inteiramente ao acaso, sendo uma ração basal isenta de proteína à base de amido (RIP) (Tab. 1), com inclusão de $40 \%$ de cada uma das cinco amostras de soja integral, totalizando seis tratamentos com oito repetições de seis aves por unidade experimental. Foi adicionada, em todas as rações experimentais, a cinza ácida insolúvel $\left(\right.$ Celite $\left.^{\mathrm{TM}}\right)$, em $1 \%$ de inclusão. Até o $23^{\circ}$ dia, as aves foram criadas recebendo ração basal, seguindo as recomendações de Rostagno et al. (2011). Posteriormente, os frangos foram alojados em gaiolas metálicas do $24^{\circ}$ ao $28^{\circ}$ dia de idade, recebendo as rações experimentais.

Tabela 1. Composição percentual da ração referência utilizada para a determinação dos valores de energia metabolizável das amostras de soja integral no primeiro experimento e composição percentual da ração isenta de proteína para a determinação do conteúdo de aminoácidos digestíveis das amostras de soja integral no segundo experimento

\begin{tabular}{|c|c|c|c|}
\hline Ração referência $^{1}$ & $(\%)$ & Ração isenta de proteína ${ }^{2}$ & $(\%)$ \\
\hline Ingredientes & & Ingredientes & \\
\hline Milho & 55,300 & Amido & 80,310 \\
\hline Farelo de soja & 37,920 & Açúcar & 5,000 \\
\hline Óleo de soja & 2,940 & Óleo de soja & 5,000 \\
\hline Fosfato bicálcico & 1,820 & Fosfato bicálcico & 2,100 \\
\hline Calcário & 0,840 & Calcário & 0,700 \\
\hline Sal comum & 0,490 & Sal comum & 0,450 \\
\hline DL-metionina (99\%) & 0,236 & Carbonato de potássio & 1,000 \\
\hline L-lisina $\mathrm{HCl}(78 \%)$ & 0,099 & Sabugo de milho & 4,000 \\
\hline L-treonina $(98 \%)$ & 0,010 & Supl. vitam. ${ }^{3}$ & 0,080 \\
\hline Supl. vitam. ${ }^{3}$ & 0,120 & Supl. min. ${ }^{4}$ & 0,150 \\
\hline Supl. $\min ^{4}$ & 0,050 & Cloreto de colina $(60 \%)$ & 0,200 \\
\hline Cloreto de colina $(60 \%)$ & 0,100 & Antioxidante $^{6}$ & 0,010 \\
\hline Anticoccidiano $^{5}$ & 0,055 & $\begin{array}{l}\text { Cinza ácida insolúvel } \\
\left(\text { Celite }^{\mathrm{TM}}\right)\end{array}$ & 1,000 \\
\hline Antioxidante $^{6}$ & 0,010 & Total & 100,000 \\
\hline Total & 100,000 & - & - \\
\hline Composição calculada & & - & - \\
\hline Energia metabolizável (kcal/kg) & 3.110 & - & - \\
\hline Proteína bruta $(\%)$ & 22,140 & - & - \\
\hline Lisina digestível (\%) & 1,160 & - & - \\
\hline Metionina digestível (\%) & 0,540 & - & - \\
\hline Metionina + Cistina digestível $(\%)$ & 0,835 & - & - \\
\hline Treonina digestível (\%) & 0,754 & - & - \\
\hline Triptofano digestível (\%) & 0,245 & - & - \\
\hline Cálcio (\%) & 0,884 & - & - \\
\hline Fósforo disponível (\%) & 0,450 & - & - \\
\hline Sódio $(\%)$ & 0,214 & - & - \\
\hline
\end{tabular}

${ }^{1}$ Ração referência utilizada para avaliar os valores de energia metabolizável das amostras de soja integral. ${ }^{2}$ RIP: dieta isenta de proteína. ${ }^{3}$ Composição por kg do produto: manganês, $75.000 \mathrm{mg}$; ferro, 20000mg; zinco, 50.000mg; cobre, $4.000 \mathrm{mg}$; cobalto, $200 \mathrm{mg}$; iodo $1.500 \mathrm{mg}$ e veículo qsp, $1.000 \mathrm{~g}$. ${ }^{4}$ Composição por $\mathrm{kg}$ do produto: vit. A, 12.000.000UI; vit. D3, 2.200.000UI; vit. E 30.000UI; vit. B1, 2.200mg; vit B2, 6.000mg; vit. B6, 3.300mg; ác. pantotênico, $13.000 \mathrm{mg}$; biotina, $110 \mathrm{mg}$; vit. K3, 2.500mg; ácido fólico, $1.000 \mathrm{mg}$; ácido nicotínico $53.0000 \mathrm{mg}$; niacina, 25.000mg; vit. B12, $16.000 \mu \mathrm{g}$; selênio, $0,25 \mathrm{~g}$; antioxidante $120.000 \mathrm{mg}$; e veículo qsp, $1.000 \mathrm{~g}$. ${ }^{5}$ Salinomicina $12 \%$. ${ }^{6}$ Butil-hidroxitolueno. 
Após um período de adaptação de quatro dias, as aves foram abatidas por eletronarcose para a coleta da digesta ileal. Para isso, as aves foram abertas na cavidade abdominal, retirando-se todo o conteúdo intestinal que estava a $40 \mathrm{~cm}$ da porção do íleo terminal, anterior à junção ileocecal. As amostras da digesta ileal foram liofilizadas a vácuo, à temperatura de $-40^{\circ} \mathrm{C}$, por 72 horas, e realizadas as análises laboratoriais para a verificação do conteúdo aminoacídico por meio de HPLC (cromatografia líquida de alta eficiência), segundo metodologia descrita por Official... (1995). Também foram determinados os teores de matéria seca e de proteína bruta das digestas segundo Silva e Queiroz (2002). A determinação do fator de indigestibilidade foi realizada de acordo com Joslyn (1970). Os cálculos da digestibilidade ileal verdadeira dos aminoácidos foram obtidos pela metodologia proposta por Sakomura e Rostagno (2007).
Os dados experimentais foram submetidos à análise variância (ANOVA) ao nível de 5\% de probabilidade, e as médias analisadas por teste Student-Newman-Keulls (SNK) a 5\%. Todas as análises foram feitas utilizando-se o software SAS (2000).

\section{RESULTADOS E DISCUSSÃO}

Com base na composição química das diferentes amostras de soja integral tostada, pode-se afirmar que esse alimento possui adequado teor de proteínas e de lipídeos, com valores próximos àqueles encontrados por Rostagno et al. (2011) de $36 \%$ de proteína bruta e $20 \%$ de extrato etéreo (Tab. 2). A amostra de soja integral número cinco teve os maiores valores de atividade de urease e de fator de inibidor de tripsina em relação às demais. Tal fato indica subprocessamento na tostagem industrial do alimento.

Tabela 2. Composição química (\% matéria natural), solubilidade proteica (\%), atividade de urease e fator inibidor de tripsina de amostras de soja integral tostada, oriundas de cinco regiões

\begin{tabular}{lccccc} 
& \multicolumn{5}{c}{ Amostras de soja integral tostada de cinco regiões } \\
\cline { 2 - 6 } Análises & 1 & 2 & 3 & 4 & 5 \\
\hline MS (\%) & 90,36 & 90,27 & 90,23 & 90,12 & 90,50 \\
PB (\%) & 34,40 & 37,33 & 35,18 & 34,29 & 36,53 \\
EE (\%) & 21,73 & 20,78 & 22,59 & 20,56 & 20,34 \\
FB (\%) & 4,71 & 2,40 & 3,32 & 3,65 & 4,50 \\
Sol. (\%) & 74,99 & 74,53 & 74,32 & 74,19 & 71,68 \\
AU (pH) & 0,05 & 0,05 & 0,05 & 0,05 & 0,36 \\
FIT (UT) & 1,36 & 1,30 & 1,24 & 1,34 & 4,2 \\
\hline
\end{tabular}

MS = matéria seca; $\mathrm{PB}=$ proteína bruta; $\mathrm{EE}=$ extrato etéreo; $\mathrm{FB}=$ fibra bruta; Sol. = solubilidade proteica em $\mathrm{KOH}(0,2 \%)$; $\mathrm{AU}=$ atividade de urease em unidades de $\mathrm{pH}$; FIT $=$ fator inibidor de tripsina (FIT) em unidades de $\mathrm{mg} / \mathrm{g}$ de proteína.

Os valores de energia bruta (EB), de energia metabolizável aparente (EMA), de energia metabolizável aparente corrigida para balanço de nitrogênio $\left(\mathrm{EMA}_{\mathrm{n}}\right)$ e $\mathrm{o}$ coeficiente de metabolizabilidade aparente corrigido para balanço de nitrogênio $\left(\mathrm{CEMA}_{\mathrm{n}}\right)$ foram próximos àqueles encontrados por Ravindran et al. (2014a) e Nunes et al. (2015). No entanto, foram inferiores aos encontrados por Valencia et al. (2009) (Tab. 3).

De acordo com Heger et al. (2016), as diferenças existentes entre as condições climáticas da região de plantio, o tipo de cultivar utilizado e, principalmente, a forma de processamento térmico empregado para o grão de soja in natura podem determinar discrepância entre os dados de composição química e no aproveitamento dos nutrientes. Ainda, esses autores afirmaram que, para um mesmo tipo de processamento, não existe padronização das condições de umidade, temperatura, tempo e pressão. No entanto, no presente estudo, não houve diferença $(\mathrm{P}>0,05)$ em relação aos teores de $\mathrm{EMA}_{n}$ e $\mathrm{CEMA}_{n}$ entre as cinco amostras de soja integral. 
Tabela 3. Valores médios de energia bruta, energia metabolizável aparente, energia metabolizável aparente corrigida para balanço de nitrogênio e coeficiente de metabolizabilidade corrigido para balanço de nitrogênio de amostras de soja integral tostada de diferentes regiões, expressos na matéria natural $(\mathrm{kcal} / \mathrm{kg})$

\begin{tabular}{lcccc}
\hline Soja integral tostada & EB & EMA & EMA $_{n}$ & CEMA $_{n}$ \\
\hline Região 1 & 5156 & $3274,50 \mathrm{ab}$ & $3152,98 \mathrm{ab}$ & $61,15 \mathrm{ab}$ \\
Região 2 & 5198 & $3416,26 \mathrm{a}$ & $3287,42 \mathrm{ab}$ & $63,24 \mathrm{ab}$ \\
Região 3 & 5297 & $3426,56 \mathrm{a}$ & $3305,70 \mathrm{ab}$ & $62,29 \mathrm{ab}$ \\
Região 4 & 5224 & $3431,36 \mathrm{a}$ & $3399,88 \mathrm{a}$ & $65,08 \mathrm{a}$ \\
Região 5 & 5232 & $3363,81 \mathrm{a}$ & $3320,63 \mathrm{ab}$ & $63,46 \mathrm{ab}$ \\
CV (\%) & & 7,0845 & 6,9375 & 7,0092 \\
\hline
\end{tabular}

$\overline{\mathrm{EB}}=$ energia bruta; $\mathrm{EMA}=$ energia metabolizável aparente; EMAn $=$ energia metabolizável aparente corrigida para balanço de nitrogênio; CEMAn = coeficiente de metabolizabilidade aparente corrigido para balanço de nitrogênio; $\mathrm{CV}=$ coeficiente de variação. ${ }^{\mathrm{a}-\mathrm{b}}$ Letras diferentes na mesma coluna diferem estatisticamente de acordo com o teste Student-Newman-Keuls $(\mathrm{P}<0,05)$.

A análise da composição dos aminoácidos verdadeiros totais dos alimentos, bem como a determinação dos teores de aminoácidos digestíveis, permite a formulação de rações com maior precisão, com balanço adequado de aminoácidos e menor impacto de poluição ambiental com a redução da excreção de nitrogênio para o meio ambiente. Os teores de aminoácidos totais para as diferentes amostras de soja integral foram semelhantes aos encontrados por Rostagno et al. (2011) e inferiores àqueles apresentados por Ravindran et al. (2014a) (Tab. $4)$.

Tabela 4. Composição percentual de aminoácidos totais de amostras de soja integral tostada, de cinco regiões diferentes, expressos na material natural

\begin{tabular}{lccccc}
\hline Aminoácidos & \multicolumn{5}{c}{ Soja integral tostada de cinco regiões } \\
\hline Lisina & 1 & 2 & 3 & 4 & 5 \\
Treonina & 2,15 & 2,44 & 2,17 & 2,12 & 2,11 \\
Metionina & 1,23 & 1,34 & 1,21 & 1,22 & 1,28 \\
Arginina & 0,29 & 0,37 & 0,33 & 0,31 & 0,34 \\
Histidina & 2,81 & 3,14 & 2,84 & 2,82 & 2,92 \\
Isoleucina & 0,93 & 1,02 & 0,91 & 0,88 & 0,91 \\
Leucina & 1,56 & 1,68 & 1,52 & 1,55 & 1,61 \\
Fenilalanina & 2,85 & 3,24 & 2,95 & 2,93 & 3,02 \\
Valina & 1,80 & 1,99 & 1,82 & 1,81 & 1,89 \\
Cistina & 1,77 & 1,95 & 1,77 & 1,74 & 1,88 \\
Alanina & 0,46 & 0,46 & 0,43 & 0,43 & 0,53 \\
Asparagina & 1,64 & 1,82 & 1,62 & 1,64 & 1,72 \\
Glutamina & 3,35 & 4,25 & 2,80 & 3,44 & 3,41 \\
Glicina & 6,37 & 7,55 & 5,93 & 6,46 & 6,58 \\
Serina & 1,72 & 1,92 & 1,79 & 1,79 & 1,88 \\
Tirosina & 1,77 & 1,96 & 1,76 & 1,72 & 1,79 \\
Prolina & 1,23 & 1,34 & 1,21 & 1,22 & 1,28 \\
\hline
\end{tabular}


Os aminoácidos oriundos das fontes proteicas adicionadas às rações não estão totalmente disponíveis para a absorção e, dessa forma, o conhecimento dos coeficientes de digestibilidade verdadeira destes, nos diferentes alimentos, torna-se imprescindível para que os nutricionistas formulem rações que possibilitem a maximização do aproveitamento pelas aves (Scottá et al., 2013). Os coeficientes de digestibilidade ileal verdadeira dos aminoácidos essenciais e não essenciais foram próximos aos encontrados por Rostagno et al. (2011). Houve diferença $(\mathrm{P}<0,05)$ entre os coeficientes de digestibilidade verdadeira dos aminoácidos essenciais, não essenciais e da proteína bruta das amostras de soja integral, e a amostra cinco apresentou os menores valores em relação às demais (Tab. 5).

Tabela 5. Valores médios dos coeficientes de digestibilidade ileal verdadeira dos aminoácidos essenciais, não essenciais e da proteína bruta de amostras de soja integral tostada de cinco regiões

\begin{tabular}{lcccccc} 
& \multicolumn{7}{c}{ Soja integral tostada de cinco regiões } & \multicolumn{1}{c}{ CV $(\%)$} \\
\hline Aminoácidos & 1 & 2 & 3 & 4 & 5 & 2,54 \\
Lisina & $92,62 \mathrm{a}$ & $93,07 \mathrm{a}$ & $92,66 \mathrm{a}$ & $92,16 \mathrm{a}$ & $85,07 \mathrm{~b}$ & 2,87 \\
Treonina & $82,49 \mathrm{a}$ & $83,08 \mathrm{a}$ & $84,01 \mathrm{a}$ & $83,96 \mathrm{a}$ & $72,14 \mathrm{~b}$ & 3,87 \\
Metionina & $92,37 \mathrm{a}$ & $90,40 \mathrm{a}$ & $91,61 \mathrm{a}$ & $95,45 \mathrm{a}$ & $84,39 \mathrm{~b}$ & 2,57 \\
Arginina & $94,07 \mathrm{a}$ & $93,11 \mathrm{a}$ & $92,52 \mathrm{a}$ & $94,19 \mathrm{a}$ & $88,77 \mathrm{~b}$ & 2,19 \\
Histidina & $97,47 \mathrm{a}$ & $97,75 \mathrm{a}$ & $93,67 \mathrm{a}$ & $93,81 \mathrm{a}$ & $81,76 \mathrm{~b}$ & 1,75 \\
Isoleucina & $89,40 \mathrm{a}$ & $88,91 \mathrm{a}$ & $86,22 \mathrm{a}$ & $89,57 \mathrm{a}$ & $80,53 \mathrm{~b}$ & 2,86 \\
Leucina & $90,35 \mathrm{a}$ & $90,39 \mathrm{a}$ & $88,17 \mathrm{a}$ & $89,93 \mathrm{a}$ & $86,05 \mathrm{~b}$ & 2,69 \\
Fenilalanina & $90,80 \mathrm{a}$ & $90,72 \mathrm{a}$ & $87,84 \mathrm{a}$ & $90,59 \mathrm{a}$ & $82,78 \mathrm{~b}$ & 2,25 \\
Valina & $86,80 \mathrm{a}$ & $85,71 \mathrm{a}$ & $83,80 \mathrm{a}$ & $86,82 \mathrm{a}$ & $77,24 \mathrm{~b}$ & 4,10 \\
CAE & $91,03 \mathrm{a}$ & $91,64 \mathrm{a}$ & $88,76 \mathrm{a}$ & $90,45 \mathrm{a}$ & $82,91 \mathrm{~b}$ & 1,74 \\
Cistina & $72,49 \mathrm{a}$ & $75,57 \mathrm{a}$ & $88,07 \mathrm{a}$ & $82,30 \mathrm{a}$ & $59,73 \mathrm{~b}$ & 5,63 \\
Alanina & $87,39 \mathrm{a}$ & $87,60 \mathrm{a}$ & $85,44 \mathrm{a}$ & $85,83 \mathrm{a}$ & $77,10 \mathrm{~b}$ & 2,76 \\
Asparagina & $90,60 \mathrm{a}$ & $91,69 \mathrm{a}$ & $90,68 \mathrm{a}$ & $91,74 \mathrm{a}$ & $83,31 \mathrm{~b}$ & 2,33 \\
Glutamina & $93,28 \mathrm{a}$ & $93,18 \mathrm{a}$ & $92,33 \mathrm{a}$ & $93,06 \mathrm{a}$ & $86,95 \mathrm{~b}$ & 1,71 \\
Glicina & $81,48 \mathrm{a}$ & $85,22 \mathrm{a}$ & $78,85 \mathrm{a}$ & $78,22 \mathrm{a}$ & $66,52 \mathrm{~b}$ & 3,96 \\
Serina & $86,72 \mathrm{a}$ & $88,74 \mathrm{a}$ & $85,29 \mathrm{a}$ & $87,73 \mathrm{a}$ & $76,74 \mathrm{~b}$ & 3,62 \\
Tirosina & $88,80 \mathrm{a}$ & $90,08 \mathrm{a}$ & $88,35 \mathrm{a}$ & $90,71 \mathrm{a}$ & $83,73 \mathrm{~b}$ & 2,69 \\
Prolina & $88,06 \mathrm{a}$ & $89,50 \mathrm{a}$ & $86,56 \mathrm{a}$ & $86,17 \mathrm{a}$ & $78,43 \mathrm{~b}$ & 3,06 \\
CANE & $88,93 \mathrm{a}$ & $90,92 \mathrm{a}$ & $88,44 \mathrm{a}$ & $89,01 \mathrm{a}$ & $80,38 \mathrm{~b}$ & 2,98 \\
CPB & $87,28 \mathrm{a}$ & $89,94 \mathrm{a}$ & $88,90 \mathrm{a}$ & $88,98 \mathrm{a}$ & $81,03 \mathrm{~b}$ & 2,21 \\
\hline
\end{tabular}

$\mathrm{CAE}=$ coeficiente de digestibilidade ileal verdadeira de aminoácidos essenciais; CANE = coeficiente de digestibilidade ileal verdadeira de aminoácidos não essenciais; $\mathrm{CPB}=$ coeficiente de digestibilidade ileal verdadeira da proteína bruta; $\mathrm{CV}=$ coeficiente de variação. ${ }^{\mathrm{a}-\mathrm{b}}$ Letras diferentes na mesma coluna diferem estatisticamente de acordo com o teste Student-Newman-Keuls $(\mathrm{P}<0,05)$.

Devido a aspectos de subprocessamento, a amostra cinco apresentou os maiores valores de atividade de urease e de fator inibidor de tripsina e menor valor de solubilidade proteica em relação às demais amostras (Tab. 2). Apesar de a amostra cinco apresentar o menor valor de solubilidade proteica, de $71,68 \%$, este se encontra dentro da faixa de 70 a $85 \%$, preconizada por Parsons et al. (1991). No entanto, os indicadores qualitativos de processamento industrial de atividade de urease e de fator de inibidor de tripsina foram de $0,36 \mathrm{e}$ 4,2, respectivamente. Estes, por sua vez, encontram-se fora dos limites recomendados por Compêndio (2005) $(0,02$ a 0,04) e por Loeffler et al. $(2012)(<4,10)$, respectivamente. Tal fato pode explicar os menores coeficientes de digestibilidade apresentados pela soja integral cinco. Como consequência, tem-se menor absorção dos aminoácidos para o crescimento, desenvolvimento e deposição proteica dos frangos. Nunes et al. (2015), ao avaliarem diferentes amostras de soja integral desativada para frangos de corte, observaram que a amostra que obteve os maiores valores de atividade de urease, consequentemente, teve os menores coeficientes médios de digestibilidade de aminoácidos digestíveis essenciais e não essenciais. Assim, as indústrias de processamento de grãos de soja devem 
proporcionar maior padronização das condições de tempo, temperatura e pressão, com o objetivo de melhorar a qualidade nutricional desse alimento.
Os valores de aminoácidos digestíveis das diferentes amostras de soja integral tostada foram semelhantes àqueles encontrados por Rostagno et al. (2011), Scottá et al. (2013) e Ravindran et al. (2014a) (Tab. 6).

Tabela 6. Valores de aminoácidos digestíveis das amostras de soja integral tostada, em porcentagem, na matéria natural

\begin{tabular}{lccccc}
\hline Aminoácidos & \multicolumn{5}{c}{ Soja integral tostada de cinco regiões } \\
\hline Lisina & 1 & 2 & 3 & 4 & 5 \\
Treonina & 1,99 & 2,27 & 2,01 & 1,95 & 1,79 \\
Metionina & 1,01 & 1,11 & 1,02 & 1,22 & 0,92 \\
Arginina & 0,27 & 0,33 & 0,30 & 0,29 & 0,29 \\
Histidina & 2,64 & 2,92 & 2,63 & 2,66 & 2,59 \\
Isoleucina & 0,90 & 0,99 & 0,85 & 0,82 & 0,74 \\
Leucina & 1,39 & 1,49 & 1,31 & 1,39 & 1,30 \\
Fenilalanina & 2,57 & 2,93 & 2,60 & 2,63 & 2,60 \\
Valina & 1,63 & 1,80 & 1,60 & 1,64 & 1,56 \\
Cistina & 1,54 & 1,67 & 1,48 & 1,51 & 1,45 \\
Alanina & 0,33 & 0,35 & 0,38 & 0,35 & 0,32 \\
Asparagina & 1,43 & 1,59 & 1,38 & 1,41 & 1,33 \\
Glutamina & 3,03 & 3,90 & 2,54 & 3,15 & 2,84 \\
Glicina & 5,94 & 7,03 & 5,47 & 6,01 & 5,72 \\
Serina & 1,40 & 1,63 & 1,41 & 1,40 & 1,25 \\
Tirosina & 1,53 & 1,74 & 1,50 & 1,51 & 1,37 \\
Prolina & 1,09 & 1,21 & 1,07 & 1,11 & 1,07 \\
\hline
\end{tabular}

Mediante os dados de composição química, de valores energéticos e, principalmente, de aminoácidos digestíveis da soja integral tostada, é possível inferir que esse alimento apresenta-se como alternativa viável na utilização como ingrediente proteico nas rações para aves. No entanto, é importante determinar a adequada relação custo-benefício de sua inclusão e pesquisar formas de se aumentar o aproveitamento dos nutrientes presentes na soja integral. Dentre esses mecanismos, a adoção de métodos industriais de tratamento térmico com maior padronização e a utilização de aditivos alimentares, como o uso de enzimas exógenas, podem contribuir de maneira eficaz. Afinal, podem ser fatores relevantes no aumento da assimilação dos nutrientes pelas aves, com consequente melhora nos índices de produtividade e lucratividade para o setor, pois reduzem a dependência da inclusão de farelo de soja.

\section{CONCLUSÃO}

A soja integral tostada apresentou-se como ingrediente proteico viável para ser utilizado na formulação de rações para frangos de corte. Não houve diferença nos valores de energia metabolizável entre as sojas integrais. No entanto, os coeficientes de digestibilidade ileal verdadeira dos aminoácidos digestíveis são diferentes. Isso indica variabilidade entre as sojas integrais provenientes de regiões distintas. Assim, recomenda-se padronização nas etapas de processamento industrial e suplementação das rações com enzimas exógenas, a fim de favorecer o uso da soja integral em larga escala.

\section{AGRADECIMENTOS}

Os autores agradecem ao apoio financeiro recebido da Capes, do CNPq e da Fapemig. 


\section{REFERÊNCIAS}

ALBINO, L.F.T.; ROSTAGNO, H.S.; FONSECA, J.B. et al. Utilização de diferentes sistemas de avaliação energética de alimentos na formulação de rações para frangos de corte. Rev. Bras. Zootec., v.21, p.1037-1046, 1992.

AUGUSTINI, M.A.B.; NUNES, R.V.; SILVA, Y.L. et al. Coeficiente de digestibilidade e valores de aminoácidos digestíveis verdadeiros de diferentes cultivares de milho para aves. Semin. Ciênc. Agrar. v.36, p.1091-1098, 2015.

CALDERANO, A.A.; GOMES, P.C.; ALBINO, L.F.T. et al. Composição química e energética de alimentos de origem vegetal determinada em aves de diferentes idades. Rev. Bras. Zootec., v.39, p.320-326, 2010 .

CARVALHO, A.A.; ZANELLA, I.; LEHNEN, C.R. et al. Digestibilidade aparente de dietas e metabolismo de frangos de corte alimentados com dietas contendo soja integral processada. Ciênc. Rural, v.38, p.477483, 2008.

COMPÊNDIO brasileiro de alimentação animal: métodos analíticos. 2.ed. São Paulo: ANFAR, 2005. $204 p$.

COSTA, E.M.S.; FIGUEIRÊDO, A.V.; MOREIRA FILHO, M.A. et al. Grão integral processado e coprodutos da soja em dietas para frangos de corte. Rev. Ciênc. Agrar., v.46, p.846-854, 2015.

HEGER, J.; WILTAFSKY, M.; ZELENKA, J. Impact of different processing of full-fat soybeans on broiler performance. Czech J. Anim. Sci., v.61, p.57-66, 2016.

JOSLYN, M.A. Methods in food analysis: physical, chemical and instrumental methods of analysis. 2.ed. New York: Academic Press, 1970. 845p.

LOEFFLER, T.; BAIRD, S.R.; BATAL, A.B. et al. Effects of trypsin inhibitor levels in soybean meal on broiler performance. Poult. Sci., 2012. Available in: < http://www.poultryscience.org/psa12/abstracts/42.pdf > Accessed in: 5 Feb. 2016.

MATTERSON, L.S.; POTTER, L.M.; STUTZ, M.W.; SINGSEN, E.P. The metabolizable energy of feed ingredients for chickens. Storrs: Agricultural Experiment Station, 1965. v.11. 11p. (Research Report).

NUNES, R.V.; BROCH, J.; POLESE, C. et al. Avaliação nutricional e energética da soja integral desativada para aves. Rev. Caatinga, v.28, p.143-151, 2015 .
OFFICIAL methods of analysis. 16.ed. Virginia: AOAC International, 1995. 1094p.

PARSONS, C.M. HASHIMOTO, K.; WEDEKIND, K.J. et al. Soybean protein solubility in potassium hydroxide: an in vitro test of in vivo protein quality. $J$. Anim. Sci., v.69, p.2918-2924, 1991.

RAVINDRAN, V.; ABDOLLAHI, M.; BOOTWALLA, S. Nutrient analysis, apparent metabolisable energy and ileal amino acid digestibility of full fat soybean for broilers. Anim. Feed Sci. Tech., v.197, p.233-240, 2014a.

RAVINDRAN, V.; ABDOLLAHI, M.; BOOTWALLA, S. Nutrient analysis, metabolizable energy, and digestible amino acids of soybean meals of different origins for broilers. Poult. Sci., v.93, p.2567-2577, 2014b.

RODRIGUES, P.B.; ROSTAGNO, H.S.; ALBINO, L.F.T. et al. Desempenho de frangos de corte, digestibilidade de nutrientes e valores energéticos de rações formuladas com vários milhos, suplementadas com enzimas. Rev. Bras. Zootec., v.32, p.171-182, 2003

ROSTAGNO, H.S.; ALBINO, L.F.T.; DONZELE J.L. et al. Tabelas brasileiras para aves e suínos: composição de alimentos e exigências nutricionais. 3.ed. Viçosa: UFV, 2011. 252p.

SAKOMURA, N.K.; ROSTAGNO, H.S. Métodos de pesquisa em nutrição de monogástricos. Jaboticabal: FUNEP, 2007. 283p.

SAS user's guide statistics. Versão 8.1. 4.ed., v.2, Cary: SAS Institute, 2000.

SCOTTÁ, B.A.; ALBINO, L.F.T.; ROSTAGNO, H.S. et al. Coeficientes de digestibilidade e conteúdo de aminoácidos digestíveis em alimentos proteicos para frangos de corte. Rev. Bras. Agropecu. Susten., v.3, p.151-157, 2013.

SILVA, D.J.; QUEIROZ, C. Análise de alimentos: métodos químicos e biológicos. 3.ed. Viçosa: UFV, 2002. 235p.

VALENCIA, D.G.; SERRANO, M.P.; JIMENÉZMORENO, E. et al. Influence of micronization (fine grinding) of soya bean meal and full-fat soya bean on the ileal digestibility of amino acids for broilers. Anim. Feed Sci. Tech., v.150, p.238-248, 2009.

VIEIRA, R.A.; ALBINO, L.F.T.; HANNAS, M.I. et al. Composição química e valores de energia metabolizável aparente corrigida de alguns alimentos energéticos determinados com frango de corte. Rev. Bras. Agropecu. Susten., v.4, p.75-83, 2014. 